\title{
Estádios de abertura floral e condicionamento em inflorescências de bastão-do-imperador ${ }^{(1)}$
}

\author{
DANIELLA NOGUEIRA MORAES CARNEIRO(2), PATRÍCIA DUARTE DE OLIVEIRA PAIVA(3), \\ LEANDRO FLÁVIO CARNEIRO(2), ROSEANE DE SOUZA RODRIGUES(4), LUIZ CARLOS DE OLIVEIRA LIMA(5), \\ GABRIELEN DE MARIA GOMES DIAS(3), RODOLFO GUIMARÃES ALEXANDRE VASQUES PEDROSO(6)
}

\begin{abstract}
RESUMO
As espécies tropicais apresentam grande importância no mercado de flores, mas informações sobre colheita e procedimentos póscolheita ainda são limitados. Para a maioria das espécies tropicais, existem poucas informações sobre soluções a serem utilizadas para condicionamento ou manutenção após a colheita. Assim, objetivou-se avaliar a durabilidade e qualidade pós-colheita de hastes florais de bastão-do-imperador em concentrações de sacarose na solução de condicionamento e diferentes estádios de abertura floral. Hastes florais foram colhidas no início da manhã e tratadas com solução de condicionamento com sacarose nas concentrações 0 (controle), 10, 20,30\% por 24h, nos três estádios de abertura floral: inflorescências com as brácteas 1/3,2/3 ou totalmente abertas. O delineamento experimental foi inteiramente casualizado, em esquema fatorial $4 \times 3 \times 6$, com 3 repetições em parcela subdividida no tempo. As avaliações foram realizadas em intervalos de 3 dias, determinando-se a massa fresca das hastes florais e avaliação de qualidade das inflorescências por meio de notas, em escala de 0 a 4 . Observou-se que a durabilidade comercial das hastes florais é maior (10 dias) quando as inflorescências são colhidas com $1 / 3$ das brácteas abertas. Recomenda-se a realização de condicionamento em hastes florais de bastão-do-imperador com concentração de $20 \%$ de sacarose por $24 \mathrm{~h}$ para inflorescências colhidas com $1 / 3$ e $2 / 3$ das brácteas abertas.
\end{abstract}

Palavras-chave: Etlingera elatior, plantas tropicais, pós-colheita, sacarose.

\section{ABSTRACT}

Developmental stage and pulsing in inflorescences of torch ginger

Tropical species are very important in the flower market, but information in harvest and postharvest procedures are not enough. There is not enough information on pulsing or holding solutions for most tropical species. The objective was to evaluate the durability and quality of postharvest torch ginger flower stems (Etlingera elatior) at sucrose concentrations in pulsing solution and different flower opening stages. Flower stems were harvested early morning at three flower opening stages: inflorescences with $1 / 3,2 / 3$ and completely open bracts, withal the stalks were pulsed with sucrose solution at concentrations of 0 (control), 10,20 , and $30 \%$ for $24 \mathrm{~h}$. Experimental design was completely randomized in a $4 \times 3 \times 6$ factorial with 3 replications in a split plot in time. Evaluations were performed every 3 days, determining the fresh weight of flowers and assessing inflorescence quality through scores on a $0-4$ point scale. Commercial vase life of stalks is longer (10 days) when inflorescences are harvested with $1 / 3$ bracts opened. It is recommended to carry out pulsing in torch ginger flower stems with concentration of $20 \%$ sucrose for $24 \mathrm{~h}$ for inflorescences harvested with $1 / 3$ or $2 / 3$ of the bracts opened.

Keywords: Etlingera elatior, tropical plants, postharvest, sucrose.

\section{INTRODUÇÃO}

Entre as flores tropicais, o bastão-do-imperador (Etlingera elatior) apresenta inflorescências muito atrativas, possui grande importância comercial (BEZERRA e LOGES, 2005). Assim como ocorre para outras espécies, um dos principais problemas da cultura é o manejo pós-colheita, geralmente realizado de forma inadequada (DIAS-TAGLIACOZZO e CASTRO, 2005).

As hastes de bastão-do-imperador são comercializadas desde a fase de botão floral em formação, com as brácteas fechadas, até com brácteas totalmente abertas, e pseudocaule com diâmetro maior que $1,0 \mathrm{~cm}$ de diâmetro (MARTÍNEZ, 2007; RIBEIRO et al., 2012). A inexistência de padronização para a maioria das flores de corte aliada à falta de tecnologia apropriada para conservação pós-colheita faz com que seja necessária a caracterização física dos produtos existentes no mercado, a fim de se conhecer a durabilidade das flores cortadas em cada fase de desenvolvimento floral (DIASTAGLIACOZZO et al., 2005).

As práticas de pós-colheita têm por objetivo a manutenção da qualidade, aumento da durabilidade e redução de perdas das inflorescências após a colheita (LOGES et al., 2005), podendo ser utilizados para a conservação pós-colheita de flores, diferentes produtos, tais como sacarose e conservantes comerciais (LUZ et al., 2005). A sacarose é o carboidrato solúvel mais utilizado nas soluções de condicionamento, pois viabiliza a absorção de água pelas hastes florais, podendo retardar a senescência e atrasar a produção de etileno das hastes florais, pois consistem na principal fonte de energia para os processos bioquímicos e fisiológicos após a colheita (NOWAK e RUDNICKI, 1990; VAN DOORN, 2001).

\footnotetext{
(1) Trabalho recebido para publicação em 03/04/2013 e aprovado em 09/09/2014

(2) Universidade Federal de Goiás (UFG), campus Jataí, Jataí-GO. Autor correspondente. daninog27@yahoo.com.br

(3) Universidade Federal de Lavras (UFLA), Departamento de Agricultura, Lavras-MG.

(4) Empresa de Pesquisa Agropecuária de Minas Gerais (EPAMIG). Fazenda Risoleta Neves. São João del Rei-MG

(5) Universidade Federal de Lavras (UFLA), Departamento de Ciência dos Alimentos, Lavras-MG.

(6) Doutorando, Universidade Federal de Lavras (UFLA), Departamento de Ciência dos Solos, Lavras-MG.
} 
O uso de sacarose em solução pós-colheita vem sendo recomendado em diferentes espécies tropicais como sorvetão (Gengibre spectabilis) (SANTOS et al., 2008) e alpínia (Alpinia purpurata) (SANT'ANNA et al., 2010). Concentrações adequadas de carboidratos em hastes florais de rosa no momento da colheita são determinantes para aumentar a durabilidade em (MARISSEN, 2001),

Para a maioria das espécies tropicais, existem poucas informações sobre a influência do estádio de abertura das brácteas na pós-colheita e quais soluções devem ser utilizadas para o condicionamento ou manutenção após a colheita. Assim, objetivou-se avaliar diferentes concentrações de sacarose na solução de condicionamento e a influência do estádio de abertura floral na durabilidade e qualidade pós-colheita de hastes florais de bastão-do-imperador.

\section{MATERIAL E MÉTODOS}

Para o experimento foram utilizadas hastes florais de bastão-do-imperador (Etlingera elatior), variedade Porcelana, colhidas no início da manhã (7h), no Município de Ijaci-MG. Imediatamente após a colheita, as hastes foram transportadas a seco, na posição horizontal, por 30 minutos, até o Laboratório de Pós-colheita de Frutos e Hortaliças do Departamento de Ciências dos Alimentos da Universidade Federal de Lavras, em Lavras-MG.
No laboratório, a porção basal das hastes foi imersa em água potável para hidratação; enquanto procedia-se a seleção das inflorescências, etiquetagem e padronização de altura em $80 \mathrm{~cm}$; até serem submetidas aos tratamentos. As hastes colhidas apresentavam diâmetro maior que $1,0 \mathrm{~cm}$.

Os tratamentos consistiram de4 (quatro) concentrações de sacarose e 3 (três) estádios de abertura floral (Figura 1). Os estádios de abertura foram: I: inflorescências com $1 / 3$ das brácteas abertas; II: inflorescências com $2 / 3$ das brácteas abertas e III: inflorescências com brácteas totalmente abertas.

Para realização do tratamento de condicionamento as hastes foram acomodadas em recipientes plásticos com capacidade de 30 litros, contendo $6 \mathrm{~L}$ de solução com sacarose (açúcar cristal) nas concentrações 0 (controle), $10,20,30 \%$ por $24 \mathrm{~h}$ e mantidas em câmara fria sob temperatura de $18^{\circ} \mathrm{C}$ e umidade relativa de $80 \%$. Após o condicionamento, as hastes foram pesadas e colocadas em recipiente plástico com capacidade de 30 litros, contendo 6L água potável, por um período de 15 dias, nas mesmas condições de armazenamento, quando da realização do condicionamento. $\mathrm{O}$ volume de água consumido foi completado a cada 3 dias.

As avaliações foram realizadas em intervalos de 3 dias, determinando-se a massa fresca relativa e avaliação de qualidade das inflorescências por meio de notas, em escala de 4 a 0 , conforme tabela 1 . As notas foram atribuídas por 3 avaliadores e calculadas as médias.
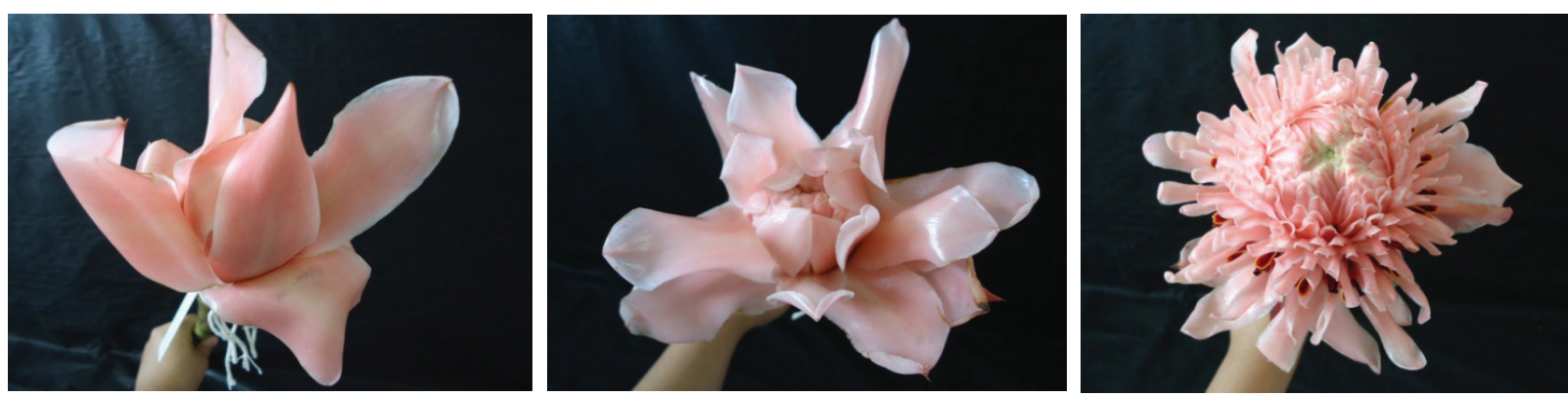

Figura 1. Estádios de abertura floral de bastão-do-imperador: I) inflorescências com 1/3 das brácteas abertas;

II) inflorescências com $2 / 3$ das brácteas abertas e III) inflorescências com brácteas totalmente abertas.

Figure 1. Floral opening stage of torch ginger: I) inflorescences with 1/3 of the bracts open;

II) inflorescences with 2/3 of the bracts open and III) inflorescences with bracts completely open.

Tabela 1. Critério de avaliação da qualidade pós-colheita de inflorescências de bastão-do-imperador por atribuição de notas. Table 1. Assessment criterion of postharvest quality of inflorescences of torch ginger stems by grading.

\begin{tabular}{l|l|l} 
NOTAS & CONCEITO & DESCRIÇÃO \\
\hline
\end{tabular}

$4 \quad$ Excelente Haste e inflorescências túrgidas, brácteas com brilho e coloração característica.

\begin{tabular}{c|c|c|c|c|c|c|} 
Bom & $\begin{array}{c}\text { Início da perda de turgescência (somente sensível ao tato); com ou sem o início do } \\
\text { desbotamento e/ou murcha das bordas das brácteas e hastes. }\end{array}$
\end{tabular}

2 Regular

\begin{tabular}{l|l|l} 
Ruim \\
\hline
\end{tabular}

$0 \quad$ Péssimo
Declínio das brácteas pela perda visível da turgescência e brilho da inflorescência e da haste. Bordos das brácteas com aspecto encharcado.

Perda da turgescência pronunciada das brácteas e/ou hastes, bordos das brácteas translúcidas, parte central da inflorescência amolecida.

Descarte: brácteas moles e/ou secas e/ou aspecto encharcado, com apodrecimento da parte central da inflorescência e abscisão das brácteas.

Fonte: adaptado de Unemoto et al. (2011). 
Para determinação do índice de durabilidade comercial de hastes florais de bastão-do-imperador, considerou a média das notas igual ou superior a 3 . O índice de durabilidade indica a qualidade que as hastes florais de bastão-do-imperador podem ser comercializadas, sendo que, abaixo desse valor, as inflorescências apresentam sinais visíveis de senescência que comprometem a apresentação do produto.

Para quantificar a massa fresca, as hastes florais foram pesadas a cada 3 dias até o descarte (15 dias após a colheita). A massa fresca relativa (MFR) foi calculada a partir da equação onde, $M F_{d}$ - massa fresca medida diariamente, $M F_{i}$ - massa fresca inicial das hastes.

O delineamento experimental utilizado foi inteiramente casualizado em esquema fatorial $4 \times 3 \times 6$, com 3 repetições, sendo o experimento instalado em parcela subdividida no tempo. As parcelas foram constituídas de 4 concentrações de sacarose x 3 estádios de abertura floral e as subparcelas, os intervalos de avaliação $(0 ; 3 ; 6 ; 9 ; 12$ e 15 dias após a colheita).

Os dados obtidos foram submetidos à análise de variância $(\mathrm{P}<0,05)$. Para os estádios de abertura floral, as médias foram comparadas pelo teste de Tukey a $5 \%$ de probabilidade e para as médias das concentrações de sacarose, foram ajustadas equações de regressão polinomial por meio do software Sistema de Análise de Variância para Dados Balanceados (Sisvar) (FERREIRA, 2011).

\section{RESULTADOS E DISCUSSÃO}

Nas avaliações qualitativas foram observadas interações significativas entre estádios de abertura floral e concentração de sacarose; estádios de abertura floral e dias após a colheita; e concentrações de sacarose e dias após a colheita e para os dados referentes amassa fresca relativa verificou-se o efeito da interação entre estádios de abertura floral e dias após a colheita.

$\mathrm{Na}$ avaliação visual da qualidade das inflorescências de bastão-do-imperador por atribuição de notas, em função, as hastes colhidas com 1/3 das brácteas abertas apresentaram avaliação da qualidade superior em relação àquelas colhidas com $2 / 3$ das brácteas abertas em todas as concentrações de sacarose utilizadas (Figura 2).

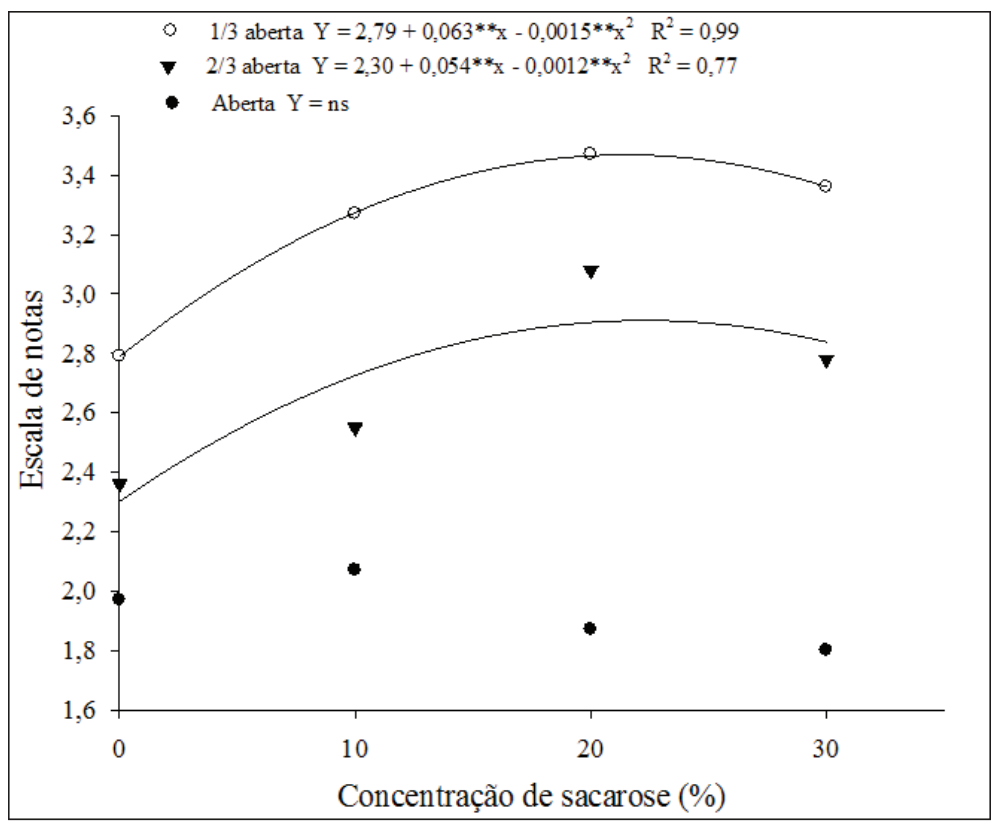

Figura 2. Avaliação de qualidade do bastão-do-imperador em função das doses de sacarose em diferentes estádios de abertura floral. Figure 2. Quality evaluation of torch ginger according at sucrose levels at different stages of flower opening.

As hastes colhidas com brácteas totalmente abertas não apresentaram correlação significativa para as concentrações de sacarose testadas. Observa-se que para as inflorescências colhidas com $1 / 3$ e $2 / 3$ das brácteas abertas, a concentração ótima de sacarose na solução de condicionamento foi de $20 \%$. Sant'Anna et al. (2012) verificaram que o condicionamento com $2 \%$ de sacarose por 12 horas, aumentou a durabilidade comercial de alpínia, tendo possibilitando que as mesmas permanecessem nos padrões de comercialização por 10,5 dias, entretanto, em concentrações superiores, ocorreu escurecimento das brácteas, comprometendo a qualidade das hastes.

Comparando os estádios de abertura floral em cada dia de avaliação, observa-se que, no terceiro dia após a colheita, inflorescências colhidas totalmente abertas apresentaram qualidade inferior em comparação com aquelas colhidas com $1 / 3$ e $2 / 3$ das brácteas abertas (Tabela 2).
Hastes florais de bastão-do-imperador colhidas com 1/3 e $2 / 3$ das brácteas abertas apresentaram um incremento na vida de vaso em seis e três dias respectivamente, quando comparadas às inflorescências com brácteas totalmente expandidas, as quais permaneceram adequadas para comercialização (índice de durabilidade $\geq 3$ ) por 6 dias. O aumento da vida de vaso propicia tanto fortalecimento econômico para produtores e comerciantes quanto maior longevidade do produto para os consumidores (PRADO et al., 2005).

Observando-se a qualidade das inflorescências em função dos dias após a colheita, essa foi decrescente, ao longo do tempo para todos os estádios de abertura floral, característico do processo de senescência (Figura 3). No entanto, observase que inflorescências colhidas com $1 / 3$ das brácteas abertas mantiveram-se com qualidade comercial (nota 3 ou superior) por aproximadamente 10 dias após a colheita, enquanto 
Tabela 2. Avaliação visual da qualidade por atribuição de notas às inflorescências de bastão-do-imperador em função de dias após a colheita (DAC) para diferentes estádios de abertura floral.

Table 2.Visual assessment of quality for grading the inflorescences of the torch ginger in function of days after harvest (DAH) for different stages of flower opening.

\begin{tabular}{|c|c|c|c|}
\hline \multirow{2}{*}{ DAC } & \multicolumn{3}{|c|}{ Estádios de abertura floral } \\
\cline { 2 - 4 } & 1/3 aberta & $2 / 3$ aberta & Aberta \\
\hline 0 & $4,0 \mathrm{~A}$ & $4,0 \mathrm{~A}$ & $4,0 \mathrm{~A}$ \\
\hline 3 & $4,0 \mathrm{~A}$ & $3,9 \mathrm{~A}$ & $3,4 \mathrm{~B}$ \\
\hline 6 & $3,8 \mathrm{~A}$ & $3,5 \mathrm{~A}$ & $2,7 \mathrm{~B}$ \\
\hline 9 & $3,1 \mathrm{~A}$ & $2,1 \mathrm{~B}$ & $1,0 \mathrm{C}$ \\
\hline 12 & $2,3 \mathrm{~A}$ & $1,5 \mathrm{~B}$ & $0,0 \mathrm{C}$ \\
\hline 15 & $1,4 \mathrm{~A}$ & $0,3 \mathrm{~B}$ & $0,0 \mathrm{~B}$ \\
\hline
\end{tabular}

Médias seguidas pela mesma letra maiúscula na linha, não diferem entre si pelo teste de Tukey, ao nível de 1\% de probabilidade.

que as colhidas com $2 / 3$ das brácteas e totalmente abertas, permaneceram por 6 e 4 dias, respectivamente. Também Dias-Tagliacozzo et al. (2003), trabalhando com outra espécie tropical, Strelitzia reginae, observaram maior longevidade das hastes florais quando colhidas com os botões totalmente fechados, em comparação com as colhidas com o primeiro florete iniciando a abertura. Dias-Tagliacozzo e Castro (2009), estudando a pós-colheita de hastes florais de Z. spectabilis, outra espécie da família Zingiberaceae, verificaram que a colheita precoce não proporcionou aumento da durabilidade comercial.

A qualidade das inflorescências em função dos dias após a colheita foi decrescente ao longo do tempo para todas as concentrações de sacarose utilizadas em pulsing (Figura 4). As hastes que não receberam sacarose apresentaram, a partir do $6^{\circ}$ dia, uma redução mais rápida na qualidade das inflorescências, caracterizada por maior senescência e, consequentemente, menor vida de vaso. Já hastes que receberam $20 \%$ de sacarose apresentaram notas superiores, durante todo o período de avaliação. Resultados semelhantes foram observados por Silva et al. (2009), onde o aumento na concentração de sacarose na solução pulsing de $2 \%$ para $20 \%$ proporcionou que as hastes de Alpinia var. Pink Ginger apresentassem incremento significativo na durabilidade comercial e longevidade total de aproximadamente 3 dias.

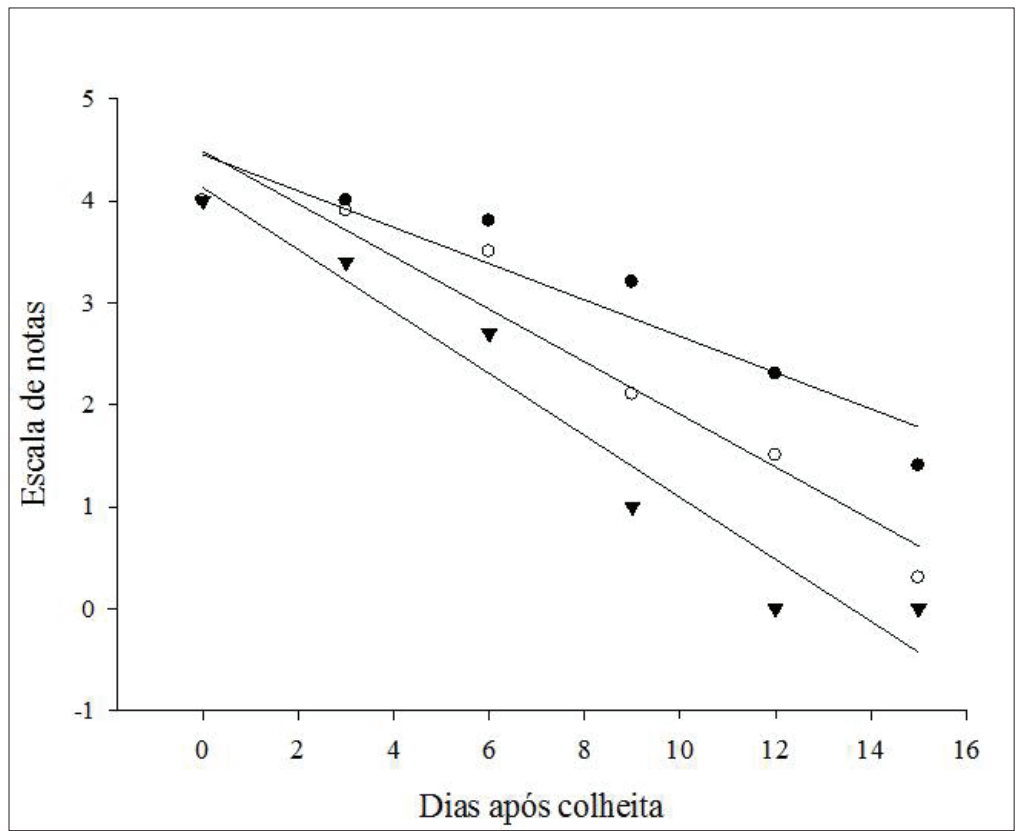

Figura 3. Avaliação da qualidade de inflorescências de bastão-do-imperador por atribuição de notas, em função dos dias após a colheita em diferentes estádios de abertura floral.

Figure 3. Quality evaluation of inflorescences of the torch ginger by grading, according to the days after harvest at different stages of flower opening. 


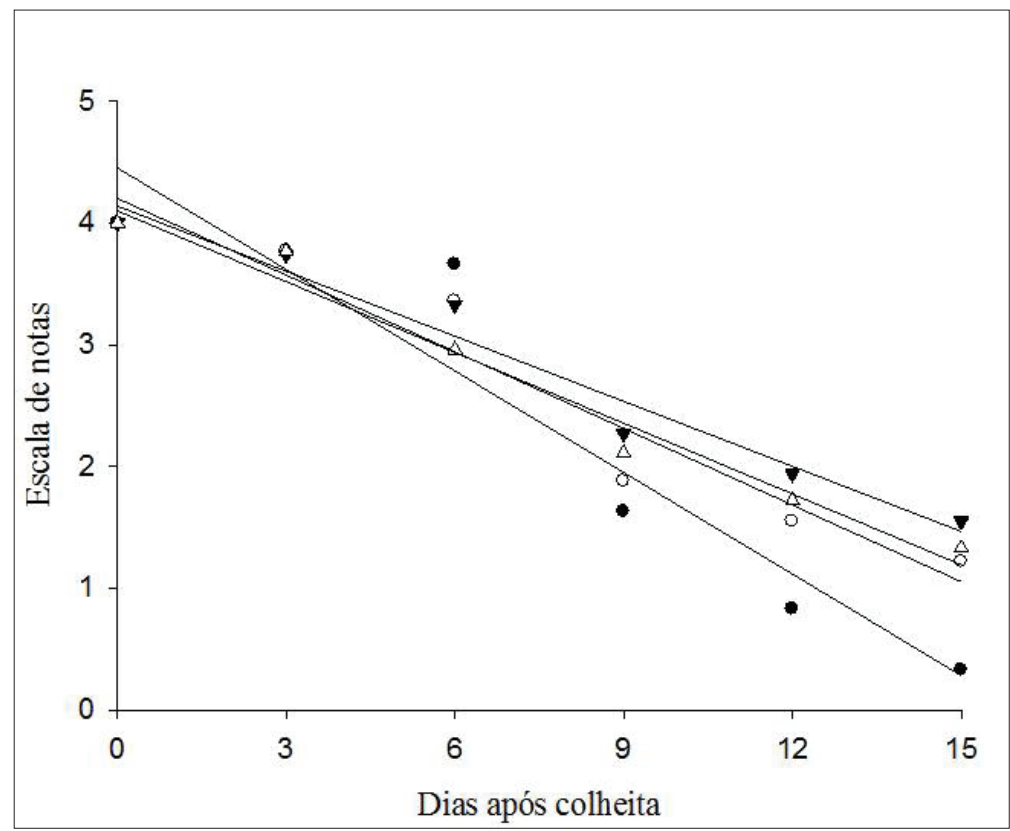

Figura 4. Avaliação de qualidade de inflorescências de bastão-do-imperador por atribuição de notas, em função dos dias após colheita em diferentes doses de sacarose.

Figure 4. Quality evaluation of inflorescences of the torch ginger by grading, according to the days after harvest in different levels of sucrose.

Apesar das inflorescências colhidas com brácteas $1 / 3$ e $2 / 3$ abertas apresentarem maior durabilidade, pode-se recomendar a colheita em diferentes estádios, podendo ser colhidas fechadas, semiabertas ou completamente abertas. A escolha pode variar com a região, época do ano, condições de cultivo, variedade, distância do mercado (LIMA et al., 2006), e considerando as características do bastão-do-imperador, a preferência do consumidor e transporte são aspectos determinantes na escolha do estádio de colheita.

Diversas espécies de flores de corte possuem a característica de não completarem a expansão de suas brácteas (GORSEL, 1994), assim como o bastão-do-imperador, quando colhido precocemente em diferentes estádios de abertura floral. Apesar de não ocorrer abertura floral, a colheita de inflorescências de bastão-do-imperador com $1 / 3$ das brácteas abertas pode facilitar o transporte e o manuseio pós-colheita, pois o espaço ocupado pelas inflorescências é menor, além de diminuir a incidência de danos nas brácteas.

Analisando-se a massa fresca relativa, que indica a porcentagem de perda durante o período de avaliação, observouse que até o $6^{\circ}$ dia após a colheita (DAC) não houve diferença significativa entre as inflorescências colhidas nos diferentes estádios de abertura floral (Tabela 3). Aos 15 DAC esses valores variaram entre os estádios de abertura floral, ocorrendo perda máxima de $11,4 \%$ para inflorescências com brácteas totalmente abertas e perda mínima de 2,5\% para as inflorescências com 1/3 de brácteas abertas. Resultados diferentes foram observados por Dias-Tagliacozzo e Castro (2009) que não observaram influência do estádio de colheita das hastes florais de Z. spectabilis, na perda de massa fresca relativa.

Tabela 3. Massa fresca relativa (\%) das hastes florais de bastão-do-imperador em função de dias após a colheita (DAC) comparando-se os diferentes estádios de abertura floral.

Table 3. Fresh weight relative (\%) of stems flower of torch ginger function of days after harvest (DAH) comparing the different stages of flower opening.

\begin{tabular}{|c|c|c|c|}
\hline \multirow{2}{*}{ DAC } & \multicolumn{3}{|c|}{ Estádio de abertura floral } \\
\cline { 2 - 4 } & $\mathbf{1 / 3}$ aberta & $\mathbf{2 / 3}$ aberta & Aberta \\
\hline 0 & $100,0 \mathrm{~A}$ & $100,0 \mathrm{~A}$ & $100,0 \mathrm{~A}$ \\
\hline 6 & $99,4 \mathrm{~A}$ & $98,4 \mathrm{~A}$ & $99,0 \mathrm{~A}$ \\
\hline 9 & $100,4 \mathrm{~A}$ & $98,7 \mathrm{~A}$ & $97,7 \mathrm{~A}$ \\
12 & $99,6 \mathrm{~A}$ & $97,1 \mathrm{AB}$ & $94,7 \mathrm{~B}$ \\
\hline 15 & $99,0 \mathrm{~A}$ & $95,4 \mathrm{AB}$ & $91,5 \mathrm{~B}$ \\
\hline Perda & $97,5 \mathrm{~A}$ & $92,8 \mathrm{~B}$ & $88,6 \mathrm{C}$ \\
\hline CV(\%) & 2,5 & 7,2 & 11,4 \\
\hline
\end{tabular}

Médias seguidas pela mesma letra na linha, não diferem entre si pelo teste de Tukey, ao nível de 1\% de probabilidade. 
Unemoto et al. (2011), em estudo pós-colheita com bastãodo-imperador, observaram variações na massa fresca entre $11 \%$ a $30 \%$, ao longo de 15 dias de avaliação, sendo que nas hastes tratadas apenas com água ocorreu uma perda de 16\%. A perda excessiva de massa fresca (água) pela transpiração e/ou obstruções dos vasos do xilema, causam murcha e, consequentemente, redução da durabilidade pós-colheita. Desse modo, hastes florais com redução entre 10 e $15 \%$ da massa fresca podem ser consideradas como murchas (NOWAK e RUDNICKI, 1990). Em diversas espécies ornamentais, o final do período da vida de vaso é caracterizado pela abscisão de partes da planta, enquanto para flores de corte, o principal sintoma de senescência caracteriza-se pela murcha (VAN DOORN, 1997).

A massa fresca relativa analisada foi decrescente em função dos dias após a colheita, para as hastes florais colhidas totalmente abertas e com 2/3 das brácteas abertas. Entretanto, para as inflorescências colhidas com $1 / 3$ das brácteas abertas não se observou redução na massa fresca ao longo do tempo (Figura 5). De acordo com Dias-Tagliacozzo e Castro (2005), a perda de massa fresca deve-se ao processo de transpiração e também à redução da condutividade de água, durante o processo de senescência da haste floral.

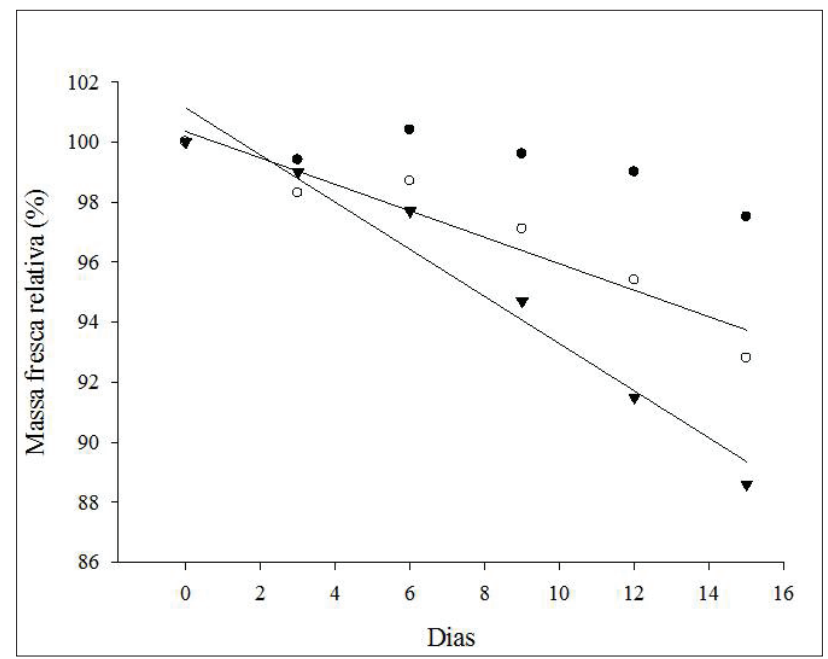

Figura 5. Massa fresca relativa (\%) das hastes de bastão-do-imperador em função dos dias após a colheita, considerando os diferentes estádios de abertura floral.

Figure 5. Fresh weight relative (\%) of torch ginger stems in function of days after harvest, considering the different stages of flower opening.

\section{CONCLUSÕES}

- A durabilidade comercial foi diretamente influenciada pelo estádio de abertura floral no momento da colheita, sendo menor (4 dias) com brácteas totalmente expandidas e máxima (10 dias) com 1/3 das brácteas.

- Independente do estádio de abertura floral, recomenda-se a realização de condicionamento em hastes florais de bastãodo-imperador com a concentração de $20 \%$ de sacarose por $24 \mathrm{~h}$.

\section{AGRADECIMENTOS}

Os autores agradecem à FAPEMIG e CNPq, pelo financiamento desse projeto. Também agradecem à professora Janice Guedes de Carvalho pela doação das hastes florais de bastão-do-imperador.

\section{REFERÊNCIAS}

ALMEIDA, E.FA.; PAIVA, P.D.O.; LIMA, L.C.O.; SILVA, F.C.; FONSECA, J.; NOGUEIRA, D.A. Calla lily inflorescences postharvest: pulsing with different sucrose concentrations and storage conditions. Ciência e Agrotecnologia, Lavras. v.35, p.657-663, 2011.

BARBOSA, J.G.; MEDEIROS, A.S.R.; FINGER, F.L.; ALVARES, V.S.; BARBOSA, M.S. Longevidade de inflorescências de lírio, de diferentes estádios de colheita, prétratadas com sacarose e tiossulfato de prata. Ciência Rural, Santa Maria. v.36, n.1, p.99-104, 2006.

BEZERRA, F.C.; LOGES, V. Zingiberaceae. In: TERAO, D.; CARVALHO, A.C.P.P.; BARROSO, T.C.S.F. (Ed.). Flores tropicais. Brasília: Embrapa Informação Tecnológica, 2005.v.1, p.103-127.

CIOTTA, M.N.; NUNES, E.C. Tratamentos pós-colheita e qualidade de hastes florais de Limonium sinuatum. Revista Brasileira de Horticultura Ornamental, Campinas, v.17, n.2, p.159-166, 2011.

DIAS-TAGLIACOSO, G.M.; CASTRO, C.E.F. Longevidade pós-colheita de Zingiber spectabile Griff. Revista Brasileira de Horticultura Ornamental, Campinas, v.15, n.2, p.127131, 2009.

DIAS-TAGLIACOSO, G.M.; CASTRO, C.E.F. Manutenção da qualidade pós-colheita de Zingiber spectabile Griff. Horticultura Brasileira, Brasília, v.23, n.2, p.563, 2005.

DIAS-TAGLIACOZZO, G.M.; ZULLO, M.A.; CASTRO, C.E.F. Caracterização física e conservação pós-colheita de alpínia. Revista Brasileira de Horticultura Ornamental, Campinas, v.9, n.1, p.17-23, 2003. 
FERREIRA, D.F. Sisvar: a computer statistical analysis system. Ciência e Agrotecnologia, Lavras, v.35, n.6, p.10391042, 2011.

GORSEL, R. Postharvest technology of imported and transshipped tropical floricultural commodities.HortScience, Alexandria, v.29, n.9, p.979-981, 1994.

HASTENREITER, F.A.; VIEIRA, J.G.Z.; FARIA, R.T. Longevidade pós-colheita de flores de Oncidium varicosum (Orchidaceae). Semina: Ciencias Agrárias. Londrina, v.27, n.1, p.27-34, 2006.

LIMA, J.D.; MORAES, W.S.; SILVA, C.M. Tecnologia póscolheita de flores de corte. São Paulo: Instituto Biológico, 2006. 7p. Disponível em: <http://www.biologico.sp.gov.br/ rifib/XIVRifib/lima.pdf>. Acesso em: 9 nov. 2012.

LOGES, V.; TEIXEIRA, M.C.F.; CASTRO, A.C.R., COSTA, A. Colheita, pós-colheita e embalagem de flores tropicais em Pernambuco. Horticultura Brasileira, Brasília, v.23, n.3, p.699-702, 2005.

LUZ, P.B.; ALMEIDA, E.F.A.; PAIVA, P.D.O.; RIBEIRO, T.R. Cultivo de flores tropicais. Informe Agropecuário, Belo Horizonte, v.26, n.227, p.62-72, 2005.

MARISSEN, N. Effects of pre-harvest light intensity and temperature on carbohydrate levels and vase life of cut roses. Acta Horticulturae, Leuven, v.543, p.331-335, 2001.

MARTÍNEZ, G. Aves del paraíso, gingers, musas y otras Zingiberales. Bogotá: EditoraHortitecnia, 2007.

NOWAK, J.; RUDNICKI, R.M. Postharvest handling and storage of cut flowers, florist greens and potted plants. Portland: Timber Press, 1990, 210p.
PRADO, R.M.; NATALE, W.; CORRÊA, M.C.M.; SILVA, J.A.A. Liming and postharvest quality of carambola fruits. Brazilian Archives of Biology and Technology, Curitiba, v.48, n.5, p.689-696, 2005.

RIBEIRO, T.R.; ALMEIDA, E.F.A.; FRAZÃO, J.E.M.; CARVALHO, J.G. Bastão-do-imperador. In: PAIVA, P.D.O.; ALMEIDA, E.F.A. (Ed.). Produção de flores de corte. Lavras: Editora UFLA, 2012, p.91-103.

SANT'ANNA, H.L.S.; SANTOS, O.S.N.; SANTOS, C.R.S.; MARTINS, C.Y.; SANTOS, M.B.; ALMEIDA, M.A.; SILVA, F.; MARTINS, G.N.; LEDO, C.A.S. Longevidade pós-colheita de alpínia [Alpinia purpurata (Vieill.) K. Schum.] tratada com soluções de sacarose e extratos aquosos naturais. Revista Brasileira de Plantas Medicinais, Botucatu, v.12, n.3, p.269277, 2010.

SANTOS, M.H.L.C.; SANTOZ, E.E.F.; LIMA, G.P.P. Soluções conservantes em sorvetão pós-colheita. Ciência Rural, Santa Maria,v.38, n.8, p.2354-2357, 2008.

SILVA, A.T.C.; FERREIRA, V.M.; GRACIANO, É.S.A.; DE SOUZA, R.C.; ARAÚJO NETO, J. C.; LOGES, V. Póscolheita de hastes de alpínia tratadas com tiossulfato de prata, sacarose e cálcio. Horticultura Brasileira, Brasília, v.27, n.3, p.357-361, 2009.

UNEMOTO, L.K.; FARIA, R.T.; TAKAHASHI, L.S.A.; ASSIS, A.M.; LONE, A.B. Longevity of torch ginger inflorescences with 1-methylcyclopropene and preservative solutions. Acta Scientiarum.Agronomy, Maringá, v.33, n.4, p.649-653, 2011.

VAN DOORN, W.G. Water relations of cut flowers. Horticultural Reviews, v.18, p.1-85, 1997.

VAN DOORN, W.G. Role of carbohydrates in flower senescence: a survey. Acta Horticulturae, Leuven, v.543, n.1, p.179-83, 2001. 